\title{
Research on Reshaping Family Education with Excellent Family Style
}

\author{
Weifeng Li ${ }^{1, \mathrm{a}}$, Lan Yao ${ }^{1, \mathrm{~b}}$ and Lixia Liang ${ }^{1, \mathrm{c}, *}$ \\ ${ }^{1}$ School Of Political Science And Law University Of Jinan, Jinan 250022, China. \\ aliweifeng96@163.com, byaolan0916@163.com, 'llxia76@163.com.
}

Keywords: family style; family education

\begin{abstract}
In China, family style and family education are closely linked. At present, family education in China is facing some new problems. It is urgent to reshape the connotation of family education with excellent family traditions and optimize the inheritance path of outstanding family traditions.
\end{abstract}

\section{Family style and family education}

Nowadays, "family education" is not strange to people. However, when it comes to "family style," it seems as if the concept is both strange and familiar. Some people even think that talking about "family style" is outdated now. So, what is meant by family style and family education? What is the relationship between the two?

\subsection{Conceptual Analysis}

\subsubsection{Family style}

The so-called Family style, as its name implies, is a family atmosphere, style and fashion. In the field of sociology, calling it "family culture" refers to the general living habits, ideological methods, moral standards and behaviors of family members in a family. It is the concrete embodiment of cultural accomplishment of family members, the quality of personality and the Interrelationships. It is a kind of style and the style advocated by parents (or ancestors) and can practice and preach, to restrain and regulate family members.[1]

Traditionally, Chinese families have always paid attention to the Family style and their emphasis on the construction of the family style has also been the foundation of many sages in history. There are more than 120 kinds of "Family Instructions" published in ancient China. From the Confucius's “Court Training” for Li Kong to the Northern Qi Dynasty thinker "Zhitui Yan’s family Instructions”, from the "Commandments Book" of Liang Zhuge, to " Blaming Sons" of Yuanming Tao, from " Xi Zhu's Family Instructions" to " Guofan Zeng's home letter " These familiar courtroom trainings are all ways to educate children how to get along with others and meet people. All of them reflect the ideological light of establishing a family home and honor the world so far.

\subsubsection{Family Education}

In the broad sense, so-called family education is each member of the family has an educational effect on the other members and the impact of such behavior, including the intergenerational influence and different generations Influence; In a narrow sense, it mainly refers to the educational activities of elders in the family to younger generations or parents to their children. In the actual discussion and people's daily understanding, especially in the narrow concept of the main.

Family existence, family education exists naturally, the history of family education in mankind can be said to be as long as the history of human family. Educating their children is an important function of the family. Family education is a prerequisite for group education. Family education is a prerequisite for group education. Without the initial shaping of individual soul by family education, one can become a person who can not be taught. Thus group education can not be carried out. Family education is the cornerstone of the entire education system.[2]

\subsection{Relationship analysis}

Family style and family education are closely linked, and the family style itself is a kind of taciturn tutor; Tutoring is the family style inheritance. 


\subsubsection{Family style is the core of family education}

Family style is the starting point for a family to start education, family style is also a consensus of the family's moral values. In traditional society, family spirits often revolve around the Confucian core values specifically to teach people to be good, proactive, industrious and frugal. It can be said that the family style is actually a mental scale formed through historical accumulation. The ancients' discussion of their family style concentrated the value and morality of the Chinese nation over family issues for thousands of years. Family style is an important part of traditional education and traditional culture. It is also the core of family education. Education within a family for future generations, both its educational goals and educational content, closely centers on the long-established family fortunes of its family.

\subsubsection{Family education is an important way to inherit the family style}

The family style has continuity. Once the family style is formed, it not only affects contemporary family members directly, but also affects future generations. Since ancient times, people all attach great importance to the shaping and inheritance of family style, and the shaping and inheritance of family style are mainly completed through family education. China's family style is inherited from generation to generation by teaching children through blood relations within the family, whose traditions are mainly transmitted through the precepts and precepts of each generation and also written in words (as mentioned above). In other words, the inheritance of family style depends on good family education, and family education is an important path inheriting the family style.

\section{The current problems that our family education faced}

Since the 1980s, great changes have taken place in our society. During the process of social transformation and economic transition, great changes have taken place in our family structure: the family scale has been gradually reduced, and the current society has entered the era of "small family age." The society is divided into small family unit, we do not have the traditional sense of the big family. Therefore, family education also faces some new problems[3]:

2.1 The emphasis on the way of raising the body ignoring the heart, so that adolescent self-centered expansion

Parents, based on compensation, always want to compensate their children for what they did not enjoy when they were young. Therefore, we should pay attention to the material needs of children and neglect the cultivation of children's mental health. As a result, the child has a bad habit of arrogance and self-determination. Especially the "421" structure of the family, the small emperor phenomenon is more serious.

\subsection{The education method of heavy intelligence and light morality makes the family education school}

School education, social education, family education have their own functions, teaching children to be the main function of family education. However, the function of family education has undergone "alienation" in recent years. Its main manifestation is the schooling of family education: what should be done in schools and what parents should do; and if schools do not demand, parents will not do it. Family education always revolves around the school's score baton, many parents put their main focus on children's learning, but neglected the cultivation of children's moral character. (A survey report from Xiamen University shows that, regardless of only-child or non-only child, parents are most concerned about children's academic performance, the second is good health, the third is the moral character.) This is very different from the family education tradition in ancient China.

\subsection{The values of eagerness to succeed, induce the high expectations of parents}

All of the world's parents have high hopes for their children, and our parents often have high expectations for their children: one is due to the cultural psychology of the traditional " Make one's ancestors illustrious"; the other is the increasingly fierce social competition , Parents want children can not lose at the starting line. As a result, parents drive their children to the established target, which may not only not motivate their children, but may cause their children to become rebellious. They may also easily lead to their own impatience and may choose to rudely educate their children. 


\subsection{Emphasis on other disciplines and ignoring self-discipline to develop ways of behavior, resulting in children to behave differently}

"If a teenager nature, habits become natural." However, the reality is not the case. Parents in the process of regulating children often use the foreign normative approach such as"The wolf is coming". The idea that children form is that social norms are a form of alien force above the human being. Their moral behavior is not voluntary but rather compelling. In other words, the moral norms of society are not internalized into individual conscious codes of conduct.

All the above drawbacks, coupled with the concern of the "second generation", "second generation" and "second generation" in recent years, also pose a very serious problem from the side: At a time of rapid economic growth and the impact of traditional family patterns, Can family education continue to assume its original heritage of outstanding traditions?

\section{Reshaping family education connotation with excellent family style}

\subsection{Family style is an important part of Chinese traditional culture.}

From a cultural point of view, family style is a characteristic of Chinese traditional culture. In traditional China, we advocate " the syncretic form of country and home," family spirits are mentioned in relation to the rise and fall of the worldly treasures and the world's survival. They have received great attention from the emperor to the common people. In addition, the family style in the accumulation of history years, naturally became an important part of Chinese culture. The various famous quotes, allusions, stories, family motto, and other precepts on the family style are as powerful as the stars, and most of the contents are of good quality and are still of guiding value and reference value today. Some scholars even think: "The history of the development of Chinese traditional culture is also a recorded history of family tradition and education."[4]

From an educational perspective, family style is the main content of traditional Chinese education. The ancient Chinese education is mainly moral education; the main ways and paths of development are "tutoring"; the basic dimensions are "uprightness, sincerity, self-cultivation, common prosperity, governing the country, peace in the world"; the basic purpose is to cultivate virtue for " becoming an adult."

\subsection{Family style can still serve as an important carrier of today's social ethics}

From tradition to modern times, Chinese society has undergone tremendous changes. However, the family style remains an indispensable asset and strength. Up to now, the core value of family style has not changed. The promotion of family style can even be said to be timely. Although the form of family style is different, they all hide the basic values of being one's own life, and point implicitly or explicitly to one's ideal personality. At this point to rebuild the building of the family style, it is necessary for us to see the positive significance of family wind for the cultivation of personality, cultivation of honor and sense of responsibility. We need to "find back" the forgotten and neglected family style and have a correct understanding of the family style in Chinese traditional culture. Those good family style advocated by each generation that have indeed played a part in people and social life , After enriching new contents, can still be used by us and can still serve as an important carrier of social morality today.

\subsection{Excellent family style should be the core of family education}

Moral education is the essence of family education. Without good virtue, even if we know more knowledge, it is hard to "become an adult." Family education should correct the deviation mentioned above from the content of education, such as paying equal attention to intelligence and morality, family education should be returned to "standard": with the aim of "moral-based" and "moral education" to educate children to develop good virtues, good quality.

It is the mission of family education to recover, shape, cultivate and inherit excellent family style. Children's living environment is mainly a family, a good family is a fertile ground for growth, good family style is an excellent ecological environment. The inheritance of family style covers all aspects of life, but in general, this kind of education generally means that children should know the way of life, the way to treat people, the way of making friends and the way of reading when they are young. Little by little, after the monasteries, these excellent family style will be internalized as 
young people's own behavior, help them get better development of society, but also make their positive quality has a good social impact .

In fact, every family has different social concepts, life attitudes and lifestyles, all of which are embodied in the abstract concept of "family style". We need to reflect on whether parents are aware of the necessity and importance of "family style" construction in family education, and whether they think and inherit the good family style. Good family style, excellent family style, directly affect the personal conduct and morality, it is the quality foundation for child to develop a good virtue. Although the family style is intangible, but the impact on children is very large, it is a subtle force of education.

\section{Excellent family tradition inheritance}

Whether or not to inherit a good family tradition relies on the parents who implement family education. In the process of excellent family tradition, parents must assume the responsibility of leading by example and precept. The mystery of family education is based on the words "imperceptible". In other words, the most fundamental principle and the most effective method of family education are to strengthen parents' self-cultivation, strive to optimize the family environment and inherit a good family tradition.

\subsection{To understand the family tradition correctly}

Parents should have a correct understanding of the traditional Chinese style of family life, not only to see the limitations of the times, but also to see its value and role. Of course, the traditional Chinese family tradition also needs to be improved with the times. We should pay attention to excluding the content of feudal ethics in traditional family traditions. To treat traditional family traditions, we should adhere to the principles of critical succession, rejection of fines, comprehensive innovation, and ancient and modern use. Criticizing inheritance means emphasizing that inheritance is a critical and selective inheritance in the new historical development. Abandoning spoilage is a way of carrying forward the essence and removing the inheritance of dross. Comprehensive innovation emphasizes that when we learn about the essence of good fortune, We should pay attention to carrying out a comprehensive and innovative work. For the purpose of ancient and modern use, we mean that we emphasize the purpose of criticizing and inheriting the traditional ethos and just want to adapt to the needs of family and social development today.

Modern family tradition, we should inject more new content, such as modern society's sense of responsibility and ethics, environmental awareness, equality, civilized and healthy way of life and so on.

\subsection{Establish the correct goal of family planning}

The correct goal is the foundation ,motivation and direction of a good family tradition. to develop and inherit it. With a common goal, we can go to a place where we want, so that one family can help each other in the same boat. In the family, the unity of life ideals and moral ideals is particularly important. It can be said to be the soul and core of the family. Wise parents should always use their lofty ideals, hard work, perseverance and optimism to influence their children and establish an enterprising family full of energy and everlasting self-improvement.

\subsection{To create a harmonious family atmosphere}

Mutual respect, understanding, trust and care among family members are prerequisites for the education of children. People's mental activity is carried out in a certain psychological living space, so a good psychological living space, including the care of parents, family members give each other warm, democratic equality, the spirit of making progress, it is a positive motivation for children's growth.

\subsection{Set a role model for parents}

Children's imitative ability is very strong. They will consciously or unconsciously imitate their parents' words and deeds when they live long-term with their parents. Affected by the family style, children are in fact influenced by their parents. Family tradition is more moisturizing subtle nurtured, reflected in the words and actions of the parents. Therefore, parents need to start from themselves, strive to broaden their horizons, have should have the values of the modern society, 
develop good habits, self-esteem, self-respect, self-love, and constantly improve their parenting skills and strict self-discipline, Work hard to make their words and deeds a model for children, which is the most effective way to educate them.

\section{References}

[1]Guojie Luo. The family tradition. Guangming Daily.1999-05-21(005).

[2]Jinfeng Zhang. New Philosophical Theory on the Importance of Family Education, Educational Theory and Practice. 10 (2005) 52-57.

[3]Liangcai Zhang. Family Education in China: Tradition, Reality and Countermeasures, Chinese Journal of Education. 30 (2006) 36-39.

[4]Jianhua Li. Home-style tutoring: Inspiring the positive energy of traditional culture. China Education Daily.2014-04-19(006). 